\title{
Experimental study of resistive load for impedance matching of triboelectric energy harvester fabricated with patterned polydimethylsiloxane polymer layer
}

\author{
Amit Sharma $^{1}$ (D) Poonam Agarwal ${ }^{1}$ (D)
}

Received: 15 October 2019 / Accepted: 23 April 2020 / Published online: 11 May 2020

C) Springer Nature Switzerland AG 2020

\begin{abstract}
Impedance matching of the power source with the external load is one of the imperative parameters of any electronic system for the optimized power transfer from the power source to the load. Mismatch in impedance of power source and the external load may cause a drastic reduction in the power transfer due to reflections. In this paper, a systematic experimental study of load matching between energy harvester and load resistance has been presented. The experimental results showed output voltage without external load condition is $68.46 \mathrm{~V}$ with the output current of $14.59 \mu \mathrm{A}$, consequently instantaneous power of $0.937 \mathrm{~mW}$. Under the optimum load of $4 \mathrm{M} \Omega$, the output power reduced to $0.248 \mathrm{~mW}$. A rigorous experimental study has been carried out under the frequency and force of $4.5 \mathrm{~Hz}$ and $2.8 \mathrm{~N}$, respectively. The triboelectric energy harvester device has also been demonstrated for the potential applications of the self-sustained system.
\end{abstract}

Keywords Triboelectric · Energy harvester · Impedance matching · Contact-separation · PDMS · Optimized load

\section{Introduction}

Energy harvesters convert the energy available in the form of light, heat, radiation, mechanical vibrations into electrical energy. The generated power can be used either to operate an electronic system directly or by storing it in the battery. The new age of technology has enabled the electronics systems to operate at low power [1, 2], which created the fascinating area of the self-powered system for various applications [3-15], e.g., wireless sensor network, biomedical, satellite, etc.

Currently, triboelectric energy harvester (TEH) is one of the dominant areas in which mechanical vibrational energy is converted into electrical energy with triboelectrification, which takes place between two materials of different tribo polarities and electrostatic induction between the tribo layer (dielectric) and electrode [16-18]. TEH has been classified into various categories, as reported by Wang [19]; in this work, the focus is on contact-separation mode TEH.

The research groups are extensively working on $\mathrm{TEH}$ devices from various aspects such as material selection, nano-material [20], fabrication process, surface morphology $[11,12,14,15,20-24]$, bulk profile $[24,25]$, etc. to enhance the device performance. But, the TEH devices are high impedance devices because these are fabricated with dielectric materials. Therefore, load matching [10-15, 20, $21,25]$ is a critical parameter for maximum power transfer

Electronic supplementary material The online version of this article (https://doi.org/10.1007/s42452-020-2820-2) contains supplementary material, which is available to authorized users.

Amit Sharma, amitsharma.ceeri@gmail.com; Poonam Agarwal, poonamgoel@mail.jnu.ac.in | ${ }^{1}$ Microsystems Lab, School of Computer and Systems Sciences, Jawaharlal Nehru University, New Delhi, India. 
to make use of the TEH device effectively. This impedance matching study is specific to the device due to its design parameters and triboelectric materials.

The main aim of this paper is to study the impact of with and without external load conditions. The experimental study has been carried out by doing the measurement with varying resistive load to find the optimum load for maximum power transfer. Brief design and fabrication detail have been discussed under Sect. 2, load varying experimental results are discussed under Sect. 3 , and the validation of the results with the reported work has been presented under Sect. 4. As proof of concept, the TEH device has been demonstrated to implement a selfpowered light-emitting diode (LED) system under Sect. 5 .

\section{Design and fabrication}

A contact-separation type triboelectric energy harvester with tribo-pair of Polydimethylsiloxane (PDMS) and Copper $(\mathrm{Cu})$, with the design parameters listed in Table 1, has been fabricated. FR4 substrate with a single side $\mathrm{Cu}$ clad has been used to implement the TEH device in which the substrate provides the mechanical support, whereas the $\mathrm{Cu}$ clad has been used as the bottom electrode. The PDMS film ( $350 \mu \mathrm{m}$ thickness) with microstructure patterns on its surface has been created using soft lithography with a Teflon mold. The PDMS layer with microstructure patterns on the surface has been fixed to the Cu clad of the FR4 substrate, keeping the patterned surface upside. The top electrode has been realized using $50 \mu \mathrm{m}$ thick $\mathrm{Cu}$ foil. The schematic and fabricated device is shown in Fig. $1 \mathrm{a}$ and $b$, respectively. The top electrode is fixed to the moving shaft of the tapping system, as illustrated in Fig. 1b. Design parameters listed in Table 1, where top electrode length and width are $60 \mathrm{~mm} \times 40 \mathrm{~mm}$. The actual overlap area is $1440 \mathrm{~mm}^{2}$ because the remaining area $\left(160 \mathrm{~mm}^{2}\right)$ left out for electrode connection. A detailed study of surface morphology and device performance has been reported [24]. The performance of the loaded device has been compared

Table 1 Design parameters

\begin{tabular}{ll}
\hline Parameter & Value \\
\hline Top electrode & \\
Length $(\mathrm{mm})$ & 60 \\
Width $(\mathrm{mm})$ & 40 \\
Bottom electrode & \\
Length $(\mathrm{mm})$ & 40 \\
Width $(\mathrm{mm})$ & 40 \\
Overlap area $\left(\mathrm{mm}^{2}\right)$ & 1440 \\
PDMS thickness $(\mu \mathrm{m})$ & $\sim 350$ \\
\hline
\end{tabular}

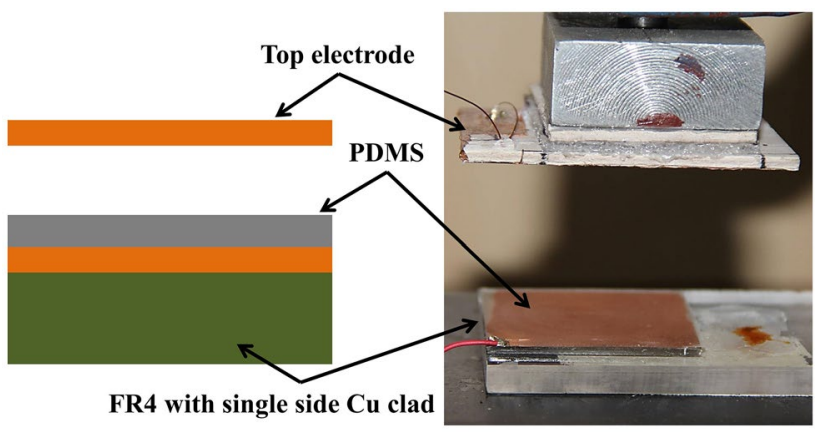

(a)

(b)

Fig. 1 Triboelectric energy harvester device a schematic presentation and $\mathbf{b}$ fabricated device

to the without external load condition, as discussed in the next section.

\section{Experimental results}

A rigorous experimental study had been carried out for the performance analysis. The vibrational impact force has been provided with force $2.8 \mathrm{~N}$ at frequency $4.5 \mathrm{~Hz}$ for the measurements. The output voltage measurement has been carried using PicoScope 3206D MSO having the internal impedance $1 \mathrm{M} \Omega \pm 1 \%$ in parallel with $14 \mathrm{pF} \pm 1 \mathrm{pF}$ and the PicoScope probe (TA386) impedance at 10X is $10 \mathrm{M} \Omega \pm 2 \%$ with $15 \mathrm{pF}$ input capacitance as per specifications. The output current has been measured using a current-to-voltage (I-to-V) converter, which converts the very low current from the TEH device into voltage [26] with a conversion ratio of $100 \mathrm{mV} / \mu \mathrm{A}$ [24]. The voltage and current have been measured simultaneously on the channel-A and channel-B of the PicoScope. The experimentally measured results of voltage, current, and instantaneous power without external load condition are shown in Figs. 2, 3 and 4, respectively, (with inset views showing the single pulse). The peak output voltage and current for the TEH device without external load are $68.46 \mathrm{~V}$ and $14.59 \mu \mathrm{A}$, respectively, resulting to the instantaneous power of $0.937 \mathrm{~mW}$, attained by multiplying the output voltage and current.

To find the optimal external load resistance, the TEH device has also been tested with varying the external resistive load ranging from $1 \mathrm{~K} \Omega$ to $18 \mathrm{M} \Omega$ with 21 different resistances. The experimentally measured output voltage, current and instantaneous power at different external load condition is listed in Table SI presented in supplementary material. The peak output current and voltage with each resistive load have been measured, and plotted with respect to resistance as represented in Fig. 5. The measured data showed that on increasing the 
Fig. 2 Voltage output waveform of TEH device without external load

Fig. 3 Current output waveform of TEH device without external load

Fig. 4 Instantaneous power output waveform of TEH device without external load


load resistance output voltage increases, whereas ohmic losses lead to decrease in output current. The variation in instantaneous power with respect to the external resistive load is illustrated in Fig. 6, which shows the optimal resistive load is of $4 \mathrm{M} \Omega$, which gives peak instantaneous power of $0.248 \mathrm{~mW}$. The experimentally measured output voltage, current and instantaneous power waveform at optimized external load resistance of $4 M \Omega$, is presented in Figs. 7, 8 and 9, respectively. Comparison in experimentally measured output voltage (Figs. 2 and 7), current (Figs. 3 and 8), and instantaneous power (Figs. 4 and 9) at without external load and optimum load are listed in Table 2. 
Fig. 5 Peak voltage and current with varying external resistive load
Fig. 6 Peak instantaneous power with varying external resistive load
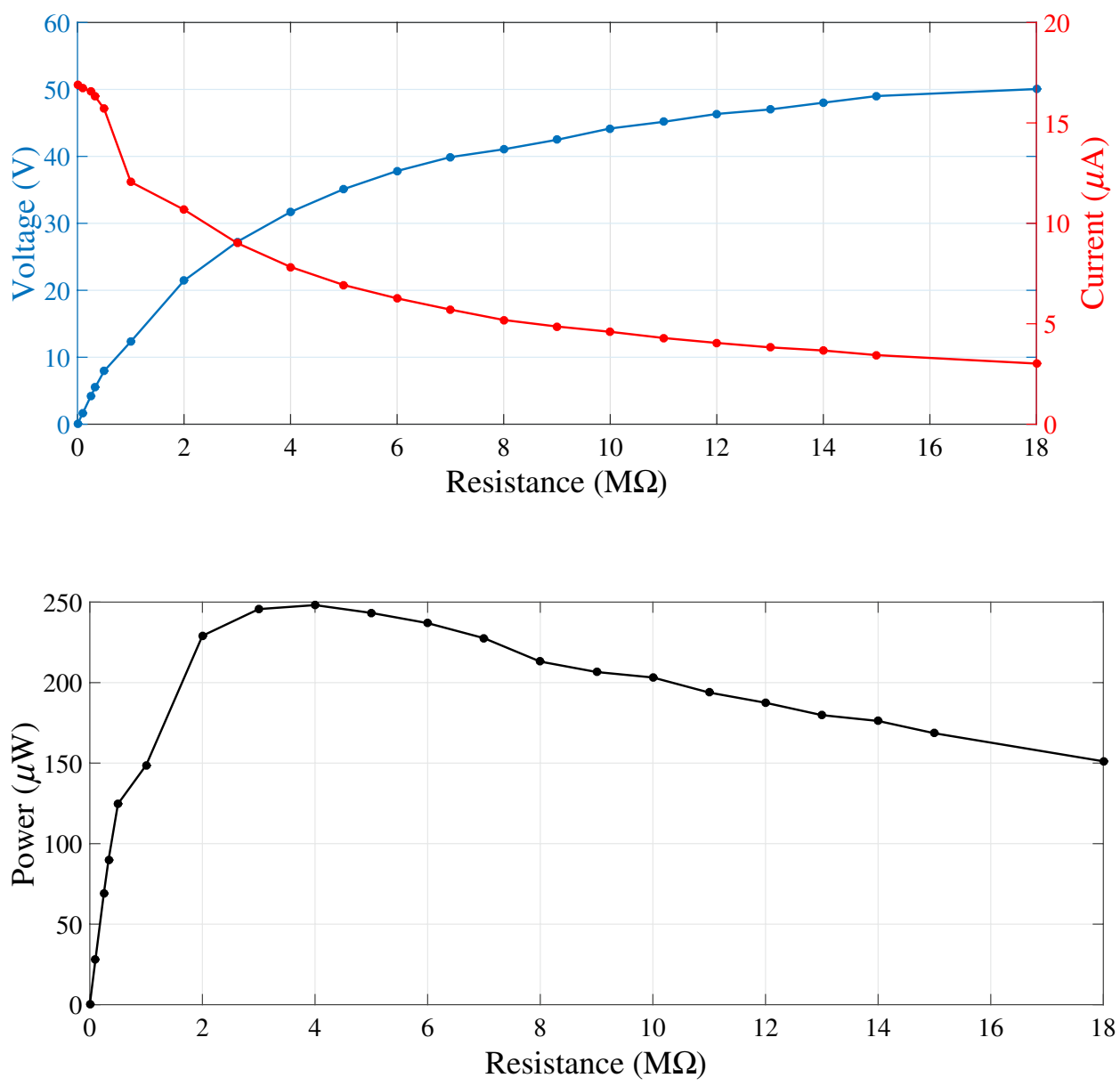

Fig. 7 Voltage output waveform of TEH device at the optimized external load of $4 \mathrm{M} \Omega$

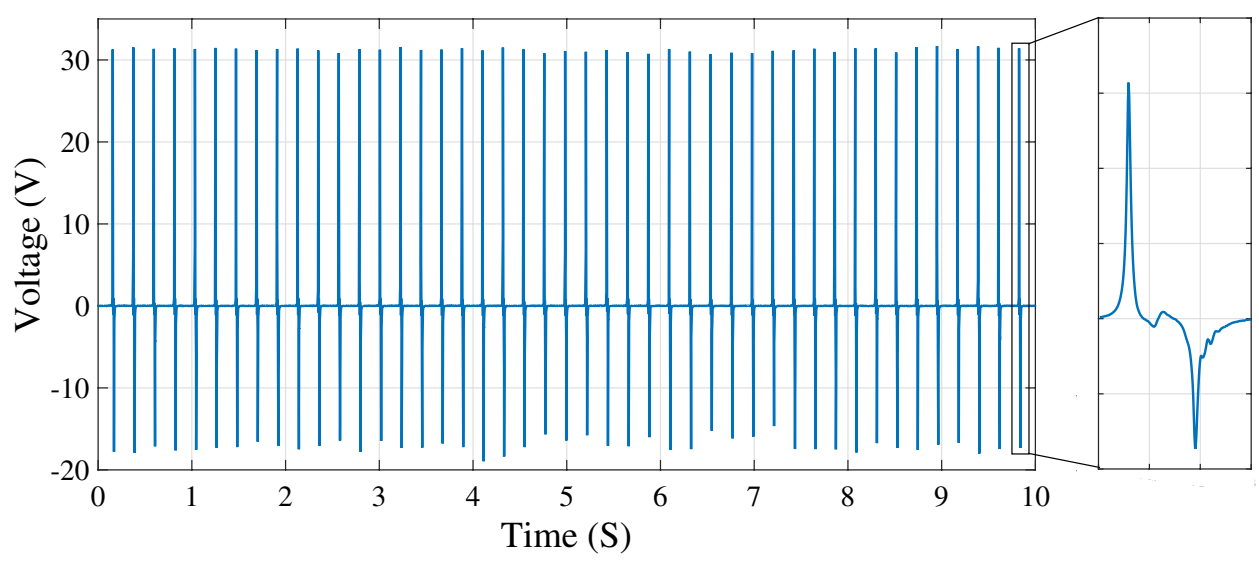

\section{Discussion}

The impact of load matching on the power transfer of the TEH device has been presented, which shows a significant reduction in power transfer even at optimized external resistive load compared to the without external load condition. Therefore, impedance matching is one of the vital deciding factors. In stringent literature survey we found many groups have reported the effect of external load, which has been compared to the without external load condition, as listed in Table 3. It is observed that in each case, output power has reduced drastically under optimal resistive load compared to without external load. This shows the devices need to be calibrated for optimal external resistive load irrespective of their 

form of TEH device at the optimized external resistive load of $4 \mathrm{M} \Omega$
Fig. 8 Current output wave-

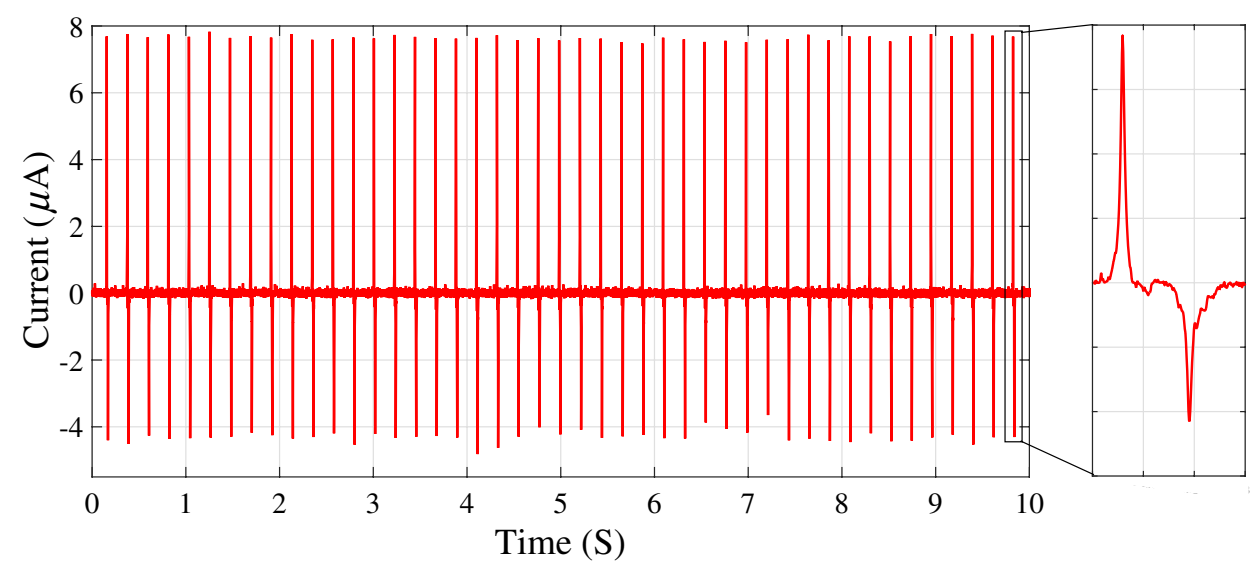

Fig. 9 Instantaneous power output waveform of TEH device at the optimized external resistive load of $4 \mathrm{M} \Omega$

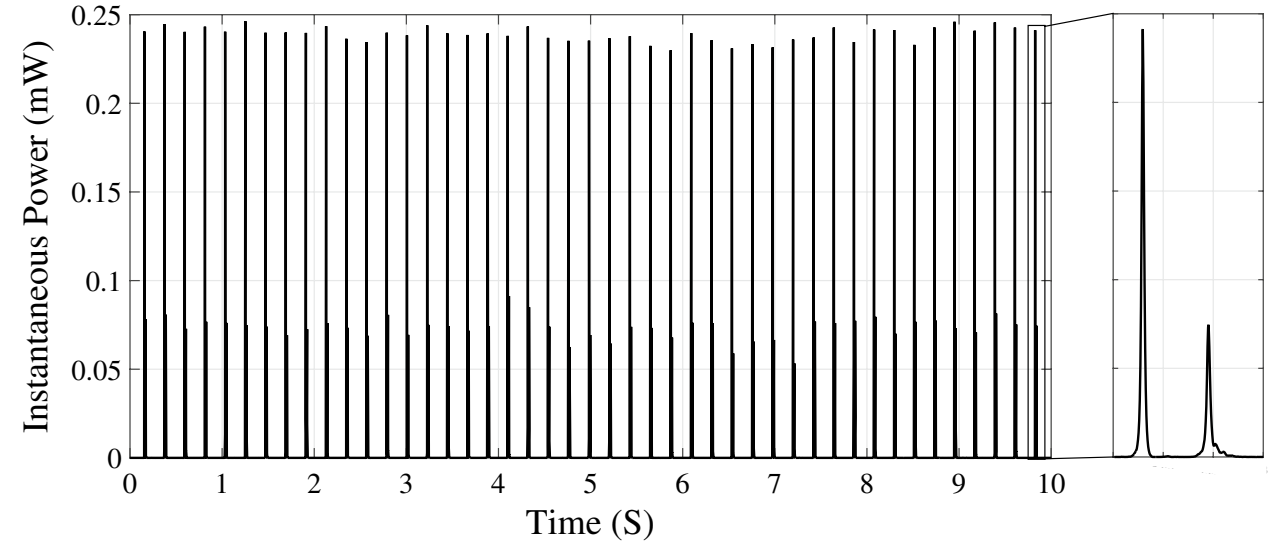

Table 2 Experimentally measured output voltage, current and instantaneous power at different load

\begin{tabular}{llll}
\hline External load & Voltage $(\mathrm{V})$ & Current $(\mu \mathrm{A})$ & $\begin{array}{l}\text { Instantane- } \\
\text { ous power } \\
(\mathrm{mW})\end{array}$ \\
\hline Without external load & 68.46 & 14.59 & 0.937 \\
$4 \mathrm{M} \Omega$ & 31.7 & 7.828 & 0.248 \\
\hline
\end{tabular}

fabrication process, tribo-pair material, device design, size, and input parameters $[11,12,14,15,20,25]$.

The fabricated TEH device can be used for various practical applications such as an acceleration sensor [10], powering portable electronics [11], as a self-powered pressure sensing system [12], as power source [9, 15] wireless system [14]. As a proof of concept, the in-house fabricated TEH device has been demonstrated in self-powered LED system, as discussed in the next section.

\section{Demonstration}

The developed TEH device has been demonstrated for the potential applications in the self-sustained system. LEDs have been connected in series and powered by the rectified electrical output from the TEH device. The full-bridge rectifier IC used is SF10M, and the LEDs are of $10 \mathrm{~mm}$ diameter, as shown in Fig. 10. The mechanical energy is provided to the TEH device using a tapping system, as shown in Fig. 10b where the top electrode is attached to the vertical movable shaft, which impacts on the TEH device placed over the platform attached to the load cell. This load cell measures the impact force of the contact between the top Cu electrode and PDMS layer, which is $2.8 \mathrm{~N}$ at $4.5 \mathrm{~Hz}$ Frequency. We could glow serially connected 52 LEDs, as presented in Fig. 10a.

\section{Conclusion}

A systematic experimental study for external load matching in the TEH device has been presented. All the measurements have been carried out at $4.5 \mathrm{~Hz}$ and $2.8 \mathrm{~N}$ force of 
Table 3 Comparison of the proposed TEH device with the reported work

\begin{tabular}{|c|c|c|c|c|c|c|c|c|}
\hline \multirow[t]{3}{*}{ References } & \multirow[t]{3}{*}{ Fabrication technique } & \multicolumn{4}{|c|}{ At optimized or matched load } & \multicolumn{3}{|c|}{ Without external load } \\
\hline & & \multirow[t]{2}{*}{ Load $(\mathrm{M} \Omega)$} & \multirow[t]{2}{*}{ Power (mW) } & \multicolumn{2}{|l|}{ Input } & \multirow[t]{2}{*}{ Power (mW) } & \multicolumn{2}{|l|}{ Input } \\
\hline & & & & Force $(\mathrm{N})$ & Frequency $(\mathrm{Hz})$ & & Force $(\mathrm{N})$ & Frequency $(\mathrm{Hz})$ \\
\hline This work & $\begin{array}{l}\text { Soft-lithography with } \\
\text { Teflon mold }\end{array}$ & 4 & 0.248 & 2.8 & 4.5 & 0.937 & 2.8 & 4.5 \\
\hline [11] & $\begin{array}{l}\text { PECVD, photolithog- } \\
\text { raphy, deposition } \\
\text { and lift-off and Si } \\
\text { mold }\end{array}$ & $\sim 3$ & 9 & - & 6 & 21.62 & - & 6 \\
\hline$[12]$ & $\begin{array}{l}\text { Au deposition by } \\
\text { sputtering, fabrica- } \\
\text { tion of wrinkled } \\
\text { CNT-PDMS film }\end{array}$ & $\sim 40 \mathrm{M} \Omega$ & $1.82 \mathrm{~mW}$ & - & 0.41 & $\begin{array}{l}\mathrm{V}_{\mathrm{OC}}=270 \mathrm{~V} \\
\mathrm{I}_{\mathrm{SC}}=21 \mu \mathrm{A} \\
(5.67 \mathrm{~mW})\end{array}$ & - & 0.41 \\
\hline [14] & $\begin{array}{l}\text { Cu and Au sput- } \\
\text { ter coating, PVA } \\
\text { nanowires prepared } \\
\text { by electrospinning }\end{array}$ & 300 & 0.23 & - & 3 & $\sim 4.125$ & Finger typing & \\
\hline$[15]$ & $\begin{array}{l}\text { Al by E-beam evapo- } \\
\text { rator, dry-etching of } \\
\text { Kapton for polymer } \\
\text { nanowires }\end{array}$ & 200 & 0.11 & - & - & 0.66 & - & \\
\hline$[20]$ & $\begin{array}{l}\text { Au by E-beam evapo- } \\
\text { rator }\end{array}$ & 1 & 420 & 500 & - & 1200 & 500 & - \\
\hline$[25]$ & $\begin{array}{l}\text { Au by thermal } \\
\text { evaporation, novel } \\
\text { triboelectric sponge } \\
\text { (TES) PDMS synthe- } \\
\text { sis with ultrasonic } \\
\text { cleaning }\end{array}$ & $10 \mathrm{M} \Omega$ & $4.41 \mathrm{~mW} / \mathrm{cm}^{2}$ & 100 & 5 & $\begin{array}{l}\mathrm{V}_{\mathrm{OC}}=280 \mathrm{~V} \\
\mathrm{I}_{\mathrm{SC}}=38 \mu \mathrm{A} / \mathrm{cm}^{2} \\
(10.64 \mathrm{~mW} / \\
\left.\mathrm{cm}^{2}\right)\end{array}$ & $50 \mathrm{~N}$ & - \\
\hline
\end{tabular}

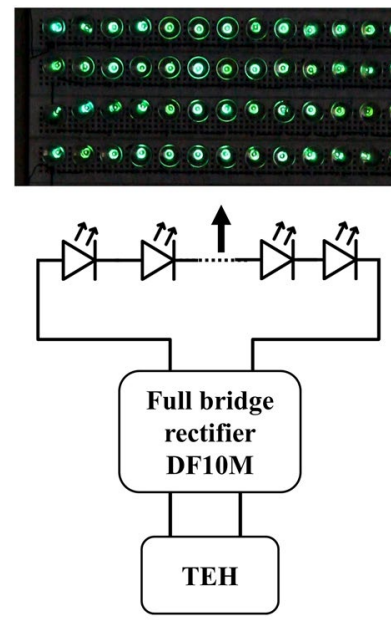

(a)

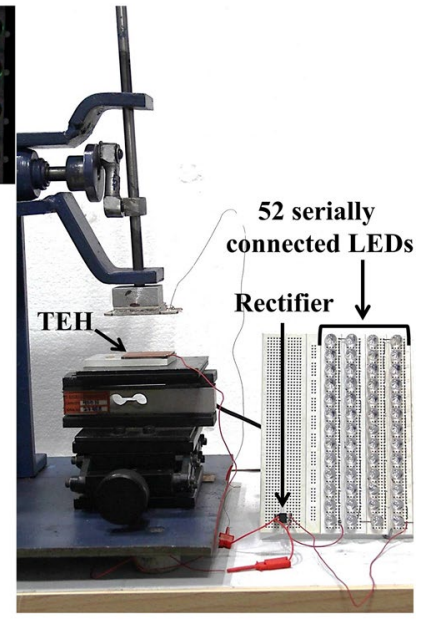

(b)
Fig. 10 Demonstration of TEH device in a 52 serially connected LED system, a schematic presentation and $\mathbf{b}$ LED set-up with tapping system tapping. The peak output voltage, current, and instantaneous power obtained without external load are $68.46 \mathrm{~V}$, $14.59 \mu \mathrm{A}$ and $0.937 \mathrm{~mW}$, respectively. Under the resistive load condition, the output voltage increases with the increase in load, whereas output current decreases. The peak instantaneous power is $0.248 \mu \mathrm{W}$ at $4 \mathrm{M} \Omega$ load. The results showed a drastic reduction in output power even on optimal external resistive load compared to the without external load, which shows the importance of impedance matching parameter which need to be addressed properly while making use of TEH device in real-time application. The TEH device has also been demonstrated for the potential applications in a self-sustained system using 52 serially connected LEDs driven by rectified output from the TEH device.

Acknowledgements The authors would like to thank DST INSPIRE FACULTY AWARD RESEARCH GRANT (IFA12-ENG-24) and DST PURSE by Department of Science and Technology, Government of India and UGC-UPE-II, JNU by University Grant Commission, Government of India for the financial support. University Science Instrumentation Center (USIC), JNU for the mechanical machining part. One of the authors would like to thank the Council of Scientific and Industrial Research (CSIR) for the research fellowship (9/263(1149)18EMR-1). 


\section{Compliance with ethical standards}

Conflict of interest The authors declare that they have no conflict of interest.

\section{References}

1. Chen J, Chen Z, Boussaid F, Zhang D, Pan X, Zhao H, Bermak A, Tsui C-Y, Wang X, Fan Z (2018) Ultra-low-power smart electronic nose system based on three-dimensional tin oxide nanotube arrays. ACS Nano 12(6):6079-6088

2. Dieffenderfer J, Goodell H, Mills S, McKnight M, Yao S, Lin F, Beppler E, Bent B, Lee B, Misra V, Zhu Y, Oralkan O, Strohmaier J, Muth J, Peden D, Bozkurt A (2016) Low-power wearable systems for continuous monitoring of environment and health for chronic respiratory disease. IEEE J Biomed Health Inform 20:1251-1264

3. Jeong CK, Park K-I, Son JH, Hwang G-T, Lee SH, Park DY, Lee HE, Lee HK, Byun M, Lee KJ (2014) Self-powered fully-flexible lightemitting system enabled by flexible energy harvester. Energy Environ Sci 7:4035-4043

4. Reddy S, He L, Ramakrishana S (2018) Miniaturized-electroneurostimulators and self-powered/rechargeable implanted devices for electrical-stimulation therapy. Biomed Signal Process Control 41:255-263

5. Chamanian S, Ulușan H, Zorlu Ö, Baghaee S, Uysal-Biyikoglu E, Külah H (2016) Wearable battery-less wireless sensor network with electromagnetic energy harvesting system. Sens Actuators A Phys 249:77-84

6. Alptekin M, Calisir T, Baskaya S (2017) Design and experimental investigation of a thermoelectric self-powered heating system. Energy Convers Manag 146:244-252

7. Yang Y, Zhu G, Zhang H, Chen J, Zhong X, Lin Z-H, Su Y, Bai P, Wen $X$, Wang ZL (2013) Triboelectric nanogenerator for harvesting wind energy and as self-powered wind vector sensor system. ACS Nano 7(10):9461-9468 PMID: 24044652

8. Xu M, Wang Y-C, Zhang SL, Ding W, Cheng J, He X, Zhang P, Wang Z, Pan X, Wang ZL (2017) An aeroelastic flutter based triboelectric nanogenerator as a self-powered active wind speed sensor in harsh environment. Extreme Mech Lett 15:122-129

9. Pallay M, Ibrahim Al, Miles RN, Towfighian S (2019) Pairing electrostatic levitation with triboelectric transduction for highperformance self-powered MEMS sensors and actuators. Appl Phys Lett 115(13):133503

10. Liu C, Wang Y, Zhang N, Yang X, Wang Z, Zhao L, Yang W, Dong L, Che L, Wang G, Zhou X (2020) A self-powered and high sensitivity acceleration sensor with V-Q-a model based on triboelectric nanogenerators (TENGs). Nano Energy 67:104228

11. Wang S, Lin L, Wang ZL (2012) Nanoscale triboelectric-effectenabled energy conversion for sustainably powering portable electronics. Nano Lett 12(12):6339-6346
12. Luo J, Fan FR, Zhou T, Tang W, Xue F, Wang ZL (2015) Ultrasensitive self-powered pressure sensing system. Extreme Mech Lett 2:28-36

13. He T, Shi Q, Wang H, Wen F, Chen T, Ouyang J, Lee C (2019) Beyond energy harvesting-multi-functional triboelectric nanosensors on a textile. Nano Energy 57:338-352

14. Zhong J, Zhong Q, Fan F, Zhang Y, Wang S, Hu B, Wang ZL, Zhou J (2013) Finger typing driven triboelectric nanogenerator and its use for instantaneously lighting up LEDs. Nano Energy 2(4):491-497

15. Zhu G, Pan C, Guo W, Chen C-Y, Zhou Y, Yu R, Wang ZL (2012) Triboelectric-generator-driven pulse electrodeposition for micropatterning. Nano Lett 12:4960-4965

16. Fan F-R, Tian ZQ, Wang ZL (2012) Flexible triboelectric generator. Nano Energy 1(2):328-334

17. Davies DK (1969) Charge generation on dielectric surfaces. J Phys D Appl Phys 2(11):1533-1537

18. Wang ZL (2013) Triboelectric nanogenerators as new energy technology for self-powered systems and as active mechanical and chemical sensors. ACS Nano 7(11):9533-9557

19. Wang ZL (2014) Triboelectric nanogenerators as new energy technology and self-powered sensors-principles, problems and perspectives. Faraday Discuss 176:447-458

20. Zhu G, Lin Z-H, Jing Q, Bai P, Pan C, Yang Y, Zhou Y, Wang ZL (2013) Toward large-scale energy harvesting by a nanoparticleenhanced triboelectric nanogenerator. Nano Lett 13:847-853

21. Nafari A, Sodano HA (2017) Surface morphology effects in a vibration based triboelectric energy harvester. Smart Mater Struct 27(1):015029

22. Sharma A, Agarwal P (2018) Impact of rough surface morphology of diluted polydimethylsiloxane (PDMS) polymer film on triboelectric energy harvester performance. In: 2018 International conference on sustainable energy, electronics, and computing systems (SEEMS), pp 1-4

23. Sharma A, Agarwal P (2020) Performance enhancement of the triboelectric energy harvester by forming rough surface polymer film using poly-dimethyl-siloxane (PDMS) +25 wt $\%$ water solution. Int J Digital Signals Smart Syst 4:40-49

24. Sharma A, Agarwal P (2019) Triboelectric energy harvester performance enhanced by modifying the tribo-layer with costeffective fabrication. Mater Res Express 6:065514

25. Kim D, Park S-J, Jeon S-B, Seol ML, Choi Y-K (2016) A triboelectric sponge fabricated from a cube sugar template by 3D soft lithography for superhydrophobicity and elasticity. Adv Electron Mater 2:1500331

26. Mallineni SSK, Behlow H, Podila R, Rao AM (2017) A low-cost approach for measuring electrical load currents in triboelectric nanogenerators. Nanotechnol Rev 7:149-156

Publisher's Note Springer Nature remains neutral with regard to jurisdictional claims in published maps and institutional affiliations. 